\title{
ANALISIS PERBANDINGAN TARIF PAJAK PENGHASILAN PASAL 17 DAN TARIF PAJAKPENGHASILAN PASAL 4 AYAT 2 (STUDY KASUS PADA CV. MELANIA)
}

\author{
Marcelino Ransulangi, \\ Herman Karamoy \\ Sonny Pangerapan \\ Fakultas Ekonomi dan Bisnis, Jurusan Akuntansi \\ Universitas Sam Ratulangi Manado \\ Email: Marcelinoransulangi@gmail.com
}

\begin{abstract}
Income tax (VAT) is a tax levied on income earned by a taxpayer or entity. Income tax article 17 and article 4, paragraph 2 is one of the taxes that are used by the taxpayer or the body to calculate the tax to be paid to the government. The purpose of this study was to determine and analyze the process of calculation of Income Tax Article 17 and Article 4 paragraph 2 so that taxpayers can know the magnitude comparison of tax payments by using Tax Article 17 and Income Tax Article 4, paragraph 2 also taxpayers can determine the article where the right to apply in the company. The research was conducted in the city of Manado on the CV. Melania. The method used in this research is descriptive method. Data collection techniques that will be done is by way of literature research, documentation, and interviews.
\end{abstract}

Keywords: Income Tax, Income Tax Article 17, Income Tax Article 4 paragraph 2.

\section{Latar Belakang}

\section{PENDAHULUAN}

Seperti halnya negara lain di dunia, Indonesia di samping menyelenggarakan pemerintahan umum juga melaksanakan pembangunan. Untuk melaksanakan pembangunan tersebut diperlukan dana yang terus meningkat sejalan dengan peningkatan volume dan dinamika pembangunan itu sendiri. Dalam rangka pemenuhan pembiayaan negara baik untuk belanja rutin maupun pembangunan, sumber penerimaan dalam negeri di luar migas semakin ditingkatkan pencapaiannya melalui penerimaan dari sektor pajak, sekaligus menjaga kemantapan dan kestabilan pendapatan negara.

Pajak adalah sektor utama sumber penerimaan negara yang cukup besar dan memberikan peranan yang sangat penting untuk membiayai pengeluaran dan belanja dari suatu negara.Setiap warga negara yang memiliki penghasilan wajib membayar Pajak Penghasilan sesuai dengan Undang-Undang Perpajakan yang ditetapkan oleh Direktorat Jenderal Pajak.Dari segi ekonomi, pajak merupakan perpindahan sumber daya dari sektor privat ke sektor publik. Bagi sektor publik, pajak akan digunakan untuk membiayai pengeluaran negara baik pengeluaran rutin maupun pembangunan, sedangkan bagi sektor privat, pajak dipandang sebagai beban. Pajak Penghasilan Pasal 17 dan Pasal 4 ayat 2 merupakan salah satu pajak langsung yang dipungut pemerintah pusat atau merupakan pajak negara yang berasal dari pendapatan rakyat.

Pajak Penghasilan (PPh) Pasal 17 dan Pasal 4 ayat 2 merupakan salah satu pajak yang memberikan masukan sangat besar bagi negara. Kebijakan pemeritah dalam mengatur Pajak Penghasilan $(\mathrm{PPh})$ antara lain dengan dikeluarkannya Undang-undang Nomor 7 tahun 1983 sebagaimana telah diubah dengan Undang-undang Nomor 10 tahun 1994, kemudian diubah kembali dalam Undang-Undang Nomor 
17 tahun 2000, dan terakhir kali diubah dalam Undang-undang Nomor 36 tahun 2008. Pajak Penghasilan $(\mathrm{PPh})$ merupakan pajak yang dikenakan atas penghasilan berupa gaji, upah, honorarium, tunjangan dan pembayaran lain dengan apapun sehubungan dengan pekerjaan, jasa atau kegiatan yang dilakukan oleh wajib pajak orang pribadi atau badan dalam negeri.

Di Indonesia sistem pemungutan pajak yang digunakan adalah Self Assesment System, yaitu sistem dimana Wajib Pajak menghitung dan melaporkan sendiri besarnya pajak yang harus disetorkan.Sistem ini diberlakukan untuk memberikan kepercayaan yang sebesar-besarnya bagi masyarakat guna meningkatkan kesadaran dan peran serta masyarakat dalam menyetorkan pajaknya. Akan tetapi, pengetahuan wajib pajak terhadap cara menghitung PPh yang digunakan saat ini yaitu PPh Pasal 4 ayat 2 masih kurang, padahal perhitungan pajak dengan pasal ini sudah diberlakukan di Indonesia. Maka penulis melakukan perbandingan besaran pajak yang harus dibayarkan sebelum (PPh pasal 17) dan sesudah menggunakan tarif pajak penghasilan $(\mathrm{PPh})$ pasal 4 ayat 2.

Berdasarkan uraian di atas, maka penulis tertarik untuk melakukan penelitian dengan judul "Analisis Perbandingan Tarif Pajak Penghasilan Pasal 17 dan Tarif Pajak Penghasilan Pasal 4 ayat 2 (Study Kasus Pada CV. MELANIA)".

\section{Tujuan Penelitian}

Tujuan dari penelitian ini adalah untuk mengetahui dan menganalisis proses perhitungan $\mathrm{PPh}$ Pasal 17 dan Pasal 4 ayat 2 agar wajib pajak dapat mengetahui besaran perbandingan pembayaran pajak dengan menggunakan PPh Pasal 17 dan PPh Pasal 4 ayat 2 juga wajib pajak dapat menentukan pasal yang tepat untuk diterapkan dalam perusahaan dilihat dari sistematis perhitungan pajak penghasilan.

\section{TINJAUAN PUSTAKA}

\section{Konsep Perpajakan \\ Definisi Pajak}

Menurut UU Nomor 28 Tahun 2007 tentang Perubahan Ketiga atas UU No.6 tahun 1983 tentang KUP (Ketentuan Umum dan Tata Cara Perpajakan) Pasal 1 butir 1 definisi pajak yaitu:

"Pajak adalah kontribusi wajib kepada negara yang terutang oleh orang pribadi atau badan yang bersifat memaksa berdasarkan Undang-undang dengan tidak mendapatkan imbalan secara langsung dan digunakan untuk keperluan negara bagi sebesar-besarnya kemakmuran rakyat".

Ilyas dan Burton (2010: 6) mengemukakan beberapa pendapat pakar tentang definisi pajak, yaitu sebagai berikut.

1. N. J. Feldman

"Pajak adalah prestasi yang dipaksakan sepihak oleh terutang kepada penguasa, (menurut normanorma yang ditetapkannya secara umum), tanpa adanya kontra prestasi, dan semata-mata digunakan untuk menutup pengeluaran-pengeluaran umum".

2. M.J.H Smeets

"Pajak adalah prestasi kepada pemerintah yang terutang melalui norma-norma umum, dan yang dapat dipaksakannya, tanpa adanya kontra prestasi yang dapat ditunjukkan dalam hal individual; maksudnya adalah untuk membiayai pengeluaran pemerintah".

3. Soeparman Soemahamidjaja

"Pajak adalah iuran wajib berupa uang atau barang, yang dipungut oleh penguasa berdasarkan norma-norma hukum, guna menutup biaya produksi barang-barang dan jasa kolektif dalam mencapai kesejahteraan umum".

Dari definisi tersebut, dapat disimpulkan bahwa pajak memiliki unsur-unsur sebagai berikut.

1. Pembayaran pajak harus berdasarkan UU. 
2. Sifatnya dapat dipaksakan.

3. Tidak ada kontra prestasi (imbalan) yang langsung dapat dirasakan oleh pembayar pajak.

4. Pemungutan pajak dilakukan oleh negara, baik oleh pemerintah pusat maupun daerah (tidak boleh dipungut oleh swasta).

5. Pajak digunakan untuk membiayai pengeluaran pemerintah (rutin dan pembangunan) bagi kepentingan masyarakat umum.

\section{Fungsi Pajak}

Umumnya pajak memiliki empat fungsi utama, yaitu sebagai berikut:

1. Fungsi budgetair

Fungsi yang terletak di sektor publik, yaitu fungsi untuk mengumpulkan uang pajak sebanyakbanyaknya sesuai dengan UU berlaku yang pada waktunya akan digunakan untuk membiayai pengeluaran-pengeluaran negara, yaitu pengeluaran rutin dan pengeluaran pembangunan dan bila ada sisa (surplus) akan digunakan sebagai tabungan pemerintah untuk investasi pemerintah.

2. Fungsi regulerend

Pajak digunakan sebagai suatu alat untuk mencapai tujuan-tujuan tertentu yang letaknya di luar bidang keuangan.Fungsi ini umumnya dapat dilihat di sektor swasta.

3. Fungsi demokrasi

Pajak sebagai suatu wujud sistem gotong-royong, termasuk kegiatan pemerintahan dan pembangunan demi kemaslahatan manusia. Fungsi demokrasi pada masa sekarang ini sering dikaitkan dengan hak seseorang apabila akan memperoleh pelayanan dari pemerintah. Apabila seseorang telah melakukan kewajibannya membayar pajak kepada negara sesuai ketentuan yang berlaku, maka ia mempunyai hak pula untuk mendapatkan pelayanan yang baik dari pemerintah.

4. Fungsi redistribusi

Pajak lebih ditekankan pada unsur pemerataan dan keadilan dalam masyarakat.Misalnya dengan adanya tarif progresif yang mengenakan pajak lebih besar kepada masyarakat yang mempunyai penghasilan besar dan pajak yang lebih kecil kepada masyarakat yang mempunyai penghasilan lebih sedikit atau kecil (Ilyas dan Burton, 2010: 12).

\section{METODE PENELITIAN}

\section{Jenis Penelitian}

Penelitian ini merupakan penelitian deskriptif, yaitu penelitian yang dilakukan untuk mengetahui dan menjelaskan variabel yang diteliti dalam suatu situasi (Sekaran, dikutip oleh Santika,2013: 6).

\section{Tempat dan Waktu Penelitian}

Adapun penelitian ini dilaksanakan pada.

Tempat : CV. MELANIA Manado

Waktu : Proses pengumpulan hingga pengolahan data penelitian ini memakan waktu 3 bulan yaitu mulai Bulan Januari - Maret 2016

\section{Metode Pengumpulan Data}

Metode yang digunakan penulis dalam pengumpulan data adalah sebagai berikut.

1. Wawancara, yaitu melakukan tanya jawab dan diskusi secara langsung dengan pihak CV. MELANIA.

2. Studi dokumentasi, yaitu dengan meneliti dokumen-dokumen keuangan perusahaan yang dapat digunakan untuk menghitung pajak perusahaan.

3. Pengamatan/observasi, yaitu dengan melakukan pengamatan dan kunjungan secara langsung pada objek untuk mendapatkan keterangan yang dibutuhkan dalam penelitian. 


\section{Metode Analisis}

Proses menganalisis dimulai dengan mengumpulkan data dan informasi dari pihak terkait di CV. MELANIA lalu mengelola data dan informasi yang diperoleh kemudian dari hasil analisis tersebut dapat ditarik kesimpulan serta saran yang dianggap perlu untuk perbaikan dalam masalah yang dihadapi.

\section{HASIL PENELITIAN DAN PEMBAHASAN}

\section{Perhitungan Pajak Penghasilan (PPh)}

\section{Pajak Penghasilan pasal 17}

Cara perhitungan PPh Pasal 17 ayat 1 (b) dan ayat 2a untuk wajib pajak badan berdasarkan UU PPh No. 36 tahun 2008 untuk pelaporan tahun pajak di atas tahun 2010 yang dikenakan atas penghasilan kena pajak dari bagian peredaran bruto sampai dengan Rp 4.800.000.000.

a. Perhitungan PPh Pasal 17 tahun 2013

Peredaran bruto Per-bulan

untuk Periode 1 Januari - 31 Desember 2013

\begin{tabular}{lcr}
\hline Januari & $\mathrm{Rp} 37.800 .000$ \\
Februari & $\mathrm{Rp} 39.650 .000$ \\
Maret & $\mathrm{Rp} 44.900 .000$ \\
April & $\mathrm{Rp} 38.550 .000$ \\
Mei & $\mathrm{Rp} 42.950 .000$ \\
Juni & $\mathrm{Rp} 45.700 .000$ \\
Juli & $\mathrm{Rp} 41.400 .000$ \\
Agustus & $\mathrm{Rp} 43.750 .000$ \\
September & $\mathrm{Rp} 47.000 .000$ \\
Oktober & $\mathrm{Rp} 49.850 .000$ \\
November & $\mathrm{Rp} 50.700 .000$ \\
Desember & $\mathrm{Rp} 52.650 .000$ \\
\hline
\end{tabular}

○ Total penghasilan bruto Rp 534.900.000

- Biaya overhead tahun $2013 \mathrm{Rp} 273.450 .000$

- Penghasilan kena pajak:

Total penghasilan bruto - Biaya overhead

Rp 534.900.000 - Rp 273.450.000 = Rp 261.450.000

- Perhitungan pajak penghasilan terhutang:

$25 \%$ x 50\% x Penghasilan Kena Pajak (PKP)

$25 \%$ x 50\% x Rp 261.450.000 = Rp 32.681.250

Dari hasil perhitungan $\mathrm{PPh}$ terhutang tahun 2013 mendapatkan hasil Rp 32.681.250 sebagai jumlah hasil pajak terhutang untuk tahun pajak 2013.

\section{Pajak Penghasilan Pasal 4 ayat 2}

Tarif pajak PPh Pasal 4 ayat 2 untuk wajib pajak badan berdasarkan PP nomor 46 tahun 2013.Besarnya tarif pajak penghasilan adalah sebesar 1\% (satu persen) dan bersifat final.Dasar pengenaan pajak yang digunakan untuk menghitung pajak penghasilan yang bersifat final tersebut adalah jumlah peredaran bruto setiap bulan.Pengenaan pajak penghasilan sebesar $1 \%$ didasarkan pada peredaran bruto dari usaha dalam 1 tahun dari tahun pajak terakhir sebelum tahun pajak yang bersangkutan.

a. Perhitungan PPh pasal 4 ayat 2 tahun 2013 
- Penjualan kotor bulan Januari-Desember 2012 adalah sebesar Rp 459.650.000. Dengan demikian perusahaan dapat menggunakan PPh pasal 4 ayat 2, karena omset perusahaan tahun 2012 lebih kecil dari Rp 4.800.000.000

$\checkmark$ Penjualan kotor bulan Januari 2013 adalah sebesar Rp 37.800.000

$\checkmark$ Penjualan kotor bulan Februari 2013 adalah sebesar Rp 39.650.000

$\checkmark$ Penjualan kotor bulan Maret 2013 adalah sebesar Rp 44.900.000

$\checkmark$ Penjualan kotor bulan April 2013 adalah sebesar Rp 38.550.000

$\checkmark$ Penjualan kotor bulan Mei 2013 adalah sebesar Rp 42.950.000

$\checkmark$ Penjualan kotor bulan Juni 2013 adalah sebesar Rp 45.700.000

$\checkmark$ Penjualan kotor bulan Juli 2013 adalah sebesar Rp Rp 41.400.000

$\checkmark$ Penjualan kotor bulan Agustus 2013 adalah sebesar Rp 43.750 .000

$\checkmark$ Penjualan kotor bulan September 2013 adalah sebesar Rp 47.000.000

$\checkmark$ Penjualan kotor bulan Oktober 2013 adalah sebesar Rp 49.850.000

$\checkmark$ Penjualan kotor bulan November 2013 adalah sebesar Rp 52.650.000

$\checkmark$ Penjualan kotor bulan Desember 2013 adalah sebesar Rp 52.650.000 berikut:

Pajak penghasilan yang harus dibayar oleh CV. Melania untuk tahun pajak 2013 adalah sebagai

\begin{tabular}{|c|c|c|c|}
\hline Masa Pajak & Peredaran Bruto & Tarif Pajak & PPh Pasal 4 ayat 2 \\
\hline Januari & 37.800 .000 & $1 \%$ & Rp 378.000 \\
\hline Februari & 39.650 .000 & $1 \%$ & $\operatorname{Rp} 396.500$ \\
\hline Maret & 44.900 .000 & $1 \%$ & Rp 449.000 \\
\hline April & 38.550 .000 & $1 \%$ & $\mathrm{Rp} 385.500$ \\
\hline Mei & 42.950 .000 & $1 \%$ & $\operatorname{Rp} 429.500$ \\
\hline Juni & 45.700 .000 & $1 \%$ & $\operatorname{Rp} 457.000$ \\
\hline Juli & 41.400 .000 & $1 \%$ & $\operatorname{Rp} 414.000$ \\
\hline Agustus & 43.750 .000 & $1 \%$ & $\operatorname{Rp} 437.500$ \\
\hline September & 47.000 .000 & $1 \%$ & Rp 470.000 \\
\hline Oktober & 49.850 .000 & $1 \%$ & $\operatorname{Rp} 498.500$ \\
\hline November & 50.700 .000 & $1 \%$ & Rp 507.000 \\
\hline Desember & Rp $\quad 52.650 .000$ & $1 \%$ & Rp 526.500 \\
\hline Total & Rp 534.900 .000 & & Rp 5.349.000 \\
\hline
\end{tabular}

Dari hasil perhitungan PPh pasal 4 ayat 2 bulan Januari s/d Desember 2013 mendapatkan hasil Rp 5.349.000 sebagai jumlah hasil pajak terhutang .

PPh Pasal 4 ayat 2 (berdasarkan PP 46 Tahun 2013) disetorkan setiap bulan, paling lambat tanggal 15 pada bulan berikutnya setelah masa pajak berakhir kecuali ditetapkan oleh Menteri Keuangan.

b. Perhitungan $\mathrm{PPh}$ pasal 4 ayat 2 tahun 2014

- Penjualan kotor bulan Januari-Desember 2013 adalah sebesar Rp 534.900.000. Dengan demikian perusahaan dapat menggunakan PPh pasal 4 ayat 2, karena omset perusahaan tahun 2013 lebih kecil dari Rp 4.800.000.000

$\checkmark$ Penjualan kotor bulan Januari 2014 adalah sebesar Rp 44.950 .000

$\checkmark$ Penjualan kotor bulan Februari 2014 adalah sebesar Rp 47.650.000

$\checkmark$ Penjualan kotor bulan Maret 2014 adalah sebesar Rp 64.800.000

$\checkmark$ Penjualan kotor bulan April 2014 adalah sebesar Rp 65.750.000

$\checkmark$ Penjualan kotor bulan Mei 2014 adalah sebesar Rp 63.400.000

$\checkmark$ Penjualan kotor bulan Juni 2014 adalah sebesar Rp 70.300.000

$\checkmark$ Penjualan kotor bulan Juli 2014 adalah sebesar Rp Rp 61.100.000 
$\checkmark$ Penjualan kotor bulan Agustus 2014 adalah sebesar Rp 69.400.000

$\checkmark$ Penjualan kotor bulan September 2014 adalah sebesar Rp 73.750.000

$\checkmark$ Penjualan kotor bulan Oktober 2014 adalah sebesar Rp 75.750.000

$\checkmark$ Penjualan kotor bulan November 2014 adalah sebesar Rp 76.500.000

$\checkmark$ Penjualan kotor bulan Desember 2014 adalah sebesar Rp 82.000.000 berikut:

Pajak penghasilan yang harus dibayar oleh CV. Melania untuk tahun pajak 2014 adalah sebagai

\begin{tabular}{lccccc}
\hline \multicolumn{1}{c}{ Masa Pajak } & Peredaran Bruto & Tarif Pajak & PPh Pasal 4 ayat 2 \\
\hline Januari & $\mathrm{Rp}$ & 44.950 .000 & $1 \%$ & $\mathrm{Rp}$ & 449.500 \\
Februari & $\mathrm{Rp}$ & 47.650 .000 & $1 \%$ & $\mathrm{Rp}$ & 476.500 \\
Maret & $\mathrm{Rp}$ & 64.800 .000 & $1 \%$ & $\mathrm{Rp}$ & 648.000 \\
April & $\mathrm{Rp}$ & 65.750 .000 & $1 \%$ & $\mathrm{Rp}$ & 657.500 \\
Mei & $\mathrm{Rp}$ & 63.400 .000 & $1 \%$ & $\mathrm{Rp}$ & 634.000 \\
Juni & $\mathrm{Rp}$ & 70.300 .000 & $1 \%$ & $\mathrm{Rp}$ & 703.000 \\
Juli & $\mathrm{Rp}$ & 61.100 .000 & $1 \%$ & $\mathrm{Rp}$ & 611.000 \\
Agustus & $\mathrm{Rp}$ & 69.400 .000 & $1 \%$ & $\mathrm{Rp}$ & 694.000 \\
September & $\mathrm{Rp}$ & 73.750 .000 & $1 \%$ & $\mathrm{Rp}$ & 737.500 \\
Oktober & $\mathrm{Rp}$ & 75.750 .000 & $1 \%$ & $\mathrm{Rp}$ & 757.500 \\
November & $\mathrm{Rp}$ & 76.500 .000 & $1 \%$ & $\mathrm{Rp}$ & 765.000 \\
Desember & $\mathrm{Rp}$ & 82.000 .000 & $1 \%$ & $\mathrm{Rp}$ & 820.000 \\
\multicolumn{1}{c}{ Total } & $\mathrm{Rp}$ & 795.350 .000 & & $\mathrm{Rp}$ & 7.953 .500 \\
\hline
\end{tabular}

Dari hasil perhitungan PPh pasal 4 ayat 2 bulan Januari s/d Desember 2014 mendapatkan hasil Rp 7.953.500 sebagai jumlah hasil pajak terhutang .

PPh Pasal 4 ayat 2 (berdasarkan PP 46 Tahun 2013) disetorkan setiap bulan, paling lambat tanggal 15 pada bulan berikutnya setelah masa pajak berakhir kecuali ditetapkan oleh Menteri Keuangan.

c. Perhitungan PPh pasal 4 ayat 2 tahun 2015

- Penjualan kotor bulan Januari-Desember 2014 adalah sebesar Rp 795.350.000. Dengan demikian perusahaan dapat menggunakan PPh pasal 4 ayat 2, karena omset perusahaan tahun 2014 lebih kecil dari Rp 4.800.000.000

$\checkmark$ Penjualan kotor bulan Januari 2015 adalah sebesar Rp 74.250.000

$\checkmark$ Penjualan kotor bulan Februari 2015 adalah sebesar Rp 79.400.000

$\checkmark$ Penjualan kotor bulan Maret 2015 adalah sebesar Rp 83.850.000

$\checkmark$ Penjualan kotor bulan April 2015 adalah sebesar Rp 82.150.000

$\checkmark$ Penjualan kotor bulan Mei 2015 adalah sebesar Rp 89.450.000

$\checkmark$ Penjualan kotor bulan Juni 2015 adalah sebesar Rp 84.800.000

$\checkmark$ Penjualan kotor bulan Juli 2015 adalah sebesar Rp Rp 79.900.000

$\checkmark$ Penjualan kotor bulan Agustus 2015 adalah sebesar Rp 85.350.000

$\checkmark$ Penjualan kotor bulan September 2015 adalah sebesar Rp 89.400.000

$\checkmark$ Penjualan kotor bulan Oktober 2015 adalah sebesar Rp 92.250.000

$\checkmark$ Penjualan kotor bulan November 2015 adalah sebesar Rp 97.000.000

$\checkmark$ Penjualan kotor bulan Desember 2015 adalah sebesar Rp 99.350.000 berikut:

Pajak penghasilan yang harus dibayar oleh CV. Melania untuk tahun pajak 2015 adalah sebagai 


\begin{tabular}{|c|c|c|c|c|c|}
\hline Masa Pajak & \multicolumn{2}{|c|}{ Peredaran Bruto } & \multirow{2}{*}{$\begin{array}{c}\text { Tarif Pajak } \\
1 \%\end{array}$} & \multicolumn{2}{|c|}{ PPh Pasal 4 ayat 2} \\
\hline Januari & $\mathrm{Rp}$ & 74.250 .000 & & $\mathrm{Rp}$ & 742.500 \\
\hline Februari & $\mathrm{Rp}$ & 79.400 .000 & $1 \%$ & $\mathrm{Rp}$ & 794.000 \\
\hline Maret & $\mathrm{Rp}$ & 83.850 .000 & $1 \%$ & $\mathrm{Rp}$ & 838.500 \\
\hline April & $\mathrm{Rp}$ & 82.150 .000 & $1 \%$ & $\mathrm{Rp}$ & 821.500 \\
\hline Mei & $\mathrm{Rp}$ & 89.450 .000 & $1 \%$ & $\mathrm{Rp}$ & 894.500 \\
\hline Juni & $\mathrm{Rp}$ & 84.800 .000 & $1 \%$ & $\mathrm{Rp}$ & 848.000 \\
\hline Juli & $\mathrm{Rp}$ & 79.900 .000 & $1 \%$ & $\mathrm{Rp}$ & 799.000 \\
\hline Agustus & $\mathrm{Rp}$ & 85.350 .000 & $1 \%$ & $\mathrm{Rp}$ & 853.500 \\
\hline September & $\mathrm{Rp}$ & 89.400 .000 & $1 \%$ & $\mathrm{Rp}$ & 894.000 \\
\hline Oktober & $\mathrm{Rp}$ & 92.250 .000 & $1 \%$ & $\mathrm{Rp}$ & 922.500 \\
\hline November & $\mathrm{Rp}$ & 97.000 .000 & $1 \%$ & $\mathrm{Rp}$ & 970.000 \\
\hline Desember & $\mathrm{Rp}$ & 99.350 .000 & $1 \%$ & $\mathrm{Rp}$ & 993.500 \\
\hline Total & \multicolumn{2}{|c|}{ Rp 1.037.350.000,- } & & \multicolumn{2}{|c|}{ Rp 10.373.500,- } \\
\hline
\end{tabular}

Dari hasil perhitungan PPh pasal 4 ayat 2 bulan Januari s/d Desember 2015 mendapatkan hasil Rp 10.373.500 sebagai jumlah hasil pajak terhutang .

PPh Pasal 4 ayat 2 (berdasarkan PP 46 Tahun 2013) disetorkan setiap bulan, paling lambat tanggal 15 pada bulan berikutnya setelah masa pajak berakhir kecuali ditetapkan oleh Menteri Keuangan.

\section{PENUTUP}

\section{Kesimpulan}

bahwa

Berdasarkan hasil penelitian dan pembahasan pada bab sebelumnya maka dapat disimpulkan

1. CV. Melania telah menjalankan kewajibannya dalam menghitung dan membayar pajak ke Negara.

2. Besaran hasil perhitungan dari Pajak Penghasilan Pasal 17 dan Pajak Penghasilan Pasal 4 ayat 2 pada CV.Melania berbeda.

3. Perhitungan Pajak Penghasilan Pasal 17 jauh lebih besar jumlah pajak yang akan dibayarkan oleh CV Melania.

4. CV Melania saat telah menggunakan PPh Pasal 4 ayat 2 dalam proses menghitung jumlah pajak terhutang, karena selain jumlah pajak yang dibayarkan lebih ringan, jenis $\mathrm{PPh}$ pasal 4 ayat 2 juga sistem perhitungannya lebih mudah untuk diterapkan.

\section{Saran}

Setelah memberikan kesimpulan dari hasil perbandingan Pajak Penghasilan Pasal 17 dengan Pasal 4 ayat 2, maka penulis juga memberikan saran sebagai berikut:

1. Perlu dilaksanakannya pencatatan yang lebih sistematis dan terorganisir dalam pembukuan dalam perusahaan agar dapat mempermudah dalam penghitungan dan penyelesaian kewajiban perpajakan.

2. Untuk meningkatkan pelayanan kepada pelanggan, agar kualitas dan kuantitas SDM dalam perusahaan dapat menjadi lebih baik. Dapat dimulai dengan struktur organisasi yang lebih terperinci atau lebih spesifik agar pelayanan yang di berikan lebih baik.

3. Kedepannya semoga pihak bisa lebih terbuka untuk memberikan data terhadap mahasiswa yang melakukan penelitian. 


\section{DAFTAR PUSTAKA}

Hery. 2008. Pengantar Akuntansi 1. Lembaga Penerbit Fakultas Ekonomi UI. Jakarta. Ilyas, Wirawan dan Burton, Richard. 2010. Hukum Pajak. Edisi Lima.Salemba Empat. Jakarta. Ilyas, Wirawan dan Burton, Richard. 2010. Hukum Pajak. Edisi Enam.Salemba Empat. Jakarta. Jennifer F. Reinganum dan Louis L. Wilde. 1985. Income Tax Compliance In A Principal-Agent Framework.http://citeseerx.ist.psu.edu/viewdoc/download?doi=10.1.1.464.2399\&rep=rep1\&type=pd $\mathrm{f}$

Kadek Trisna Dwiyanti dan Made Sukartha.2013. Pengaruh Perubahan Tarif Pajak Penghasilan Badan Tahun $2010 \quad$ Pada Manajemen Laba.http://download.portalgaruda.org/article.php?article=82276\&val=986

Luh Gita Andini A. P. dan I Kadek Sumadi. 2014. Analisis Penerapan Tax review Atas Pajak Penghasilan Badan Dan Withholding Tax http://download.portalgaruda.org/article.php? article=195930\&val=986\&title=ANALISIS\%20PENERAP AN\%20TAX\%20REVIEW\%20ATAS\%20PAJAK\%20PENGHASILAN\%20BADAN\%20DAN\%20WIT HHOLDING\%20TAX\%20PADA\%20HOTEL\%20X

Mankiw, N. Gregory, Matthew Charles Weinzierl, dan Danny Ferris Yagan. 2009. Optimal Taxation In Theory And Practice. https://dash.harvard.edu/bitstream/handle/1/4263739/Mankiw_OptimalTaxationTheory.pdf?sequence=2 Mardiasmo. 2011. Perpajakan. Edisi revisi 2011.ANDI. Jakarta.

Michael G. Allingham \& Agnar Sandmo. 1972. Income Tax Evasion : A Theoretical Analysis. http://www3.nccu.edu.tw/ klueng/tax\%20paper/1.pdf

Nurul Ifadhoh. 2013. Implementasi Tax Planing Pajak Penghasilan Badan PT. Indojaya Mandiri.http://ejournal.stiesia.ac.id/index.php/jira/article/viewFile/205/208

Renita Rumuy. 2012. Penerapan Perencanaan Pajak Penghasilan Badan Sebagai Upaya Efisiensi $\begin{array}{llll}\text { Pembayaran Pajak Pasongko. } & \text { Sinar }\end{array}$ http://eprints.mdp.ac.id/706/1/jurnal\%202009210045\%20Renita_Rumuy.Pdf

Republik Indonesia, Undang-Undang Nomor 28 Tahun 2007 Tentang Ketentuan Umum dan Tata Cara Perpajakan

Rifaldi Josua Muaja. 2015. Analisis Penerapan Perencanaan Pajak Pada Wajib Pajak Badan di PT. Elsadai Servo Cons. http://ejournal.unsrat.ac.id/index.php/emba/article/download/10586/10173

Rima Naomi Pangemanan. 2013. Hubungan Jumlah Dan Kepatuhan Wajib Pajak Badan Dengan Penerimaan PPh KPP

Manado.http://ejournal.unsrat.ac.id/index.php/emba/article/download/1886/1489

Sugiyono, 2007.Metode Penelitian Bisnis. Alfabeta. Bandung. 